\title{
Catatonia in depression: prevalence, clinical correlates, and validation of a scale
}

\author{
Sergio E Starkstein, Gustavo Petracca, Alejandra Tesón, Erán Chemerinski, \\ Marcelo Merello, Ricardo Migliorelli, Ramón Leiguarda
}

\begin{abstract}
Objectives-To examine the clinical correlates of catatonia in depression, to validate a scale for catatonia, and to assess the validity of the DSM-IV criteria of the catatonic features specifier for mood disorders.

Methods-A series of 79 consecutive patients with depression and 41 patients with Parkinson's disease without depression were examined using the modified Rogers scale (MRS), the unified Parkinson's disease rating scale (UPDRS), and the structured clinical interview for DSM-III-R (SCID).

Results-Sixteen of the 79 depressed patients $(20 \%)$ had catatonia. Depressed patients with catatonia had significantly higher scores on the MRS than non-catatonic depressed patients matched for severity of depression, or non-depressed patients with Parkinson's disease matched for severity of motor impairment. Depressed patients with catatonia were older, had a significantly higher frequency of major depression, more severe cognitive impairments, and more severe deficits in activities of daily living than depressed non-catatonic patients. The DSM-IV criteria of catatonia separated depressed catatonic patients from patients with Parkinson's disease matched for motor impairment, with a specificity of $100 \%$. Catatonic signs did not improve after apomorphine.

Conclusions-catatonia is most prevalent among elderly patients with severe depression. The study showed the validity of the MRS for the diagnosis of catatonia in depressed patients, as well as the specificity of the DSM-IV criteria of the catatonic features specifier.
\end{abstract}

$(F$ Neurol Neurosurg Psychiatry 1996;60:326-332)

Keywords: catatonia; depression; dopamine; Parkinson's disease

In 1843 the French psychiatrist Baillarger described a delusional syndrome in alienated patients occurring in a state of stupor, with fixed gaze, a facial expression of frozen astonishment, muteness, and indifference. ${ }^{1}$ As these patients also had suicidal ideation, Baillarger termed this state "melancholie avec stupeur". Thirty nine years later, Kahlbaum described a state "in which the patient remains completely mute and immobile, with staring expression, gaze fixed into space, with an apparent complete loss of will, no reaction to sensory stimuli, sometimes with the symptom of waxy flexibility completely developed, as in catalepsy, sometimes of a mild degree, but clearly recognisable," and labelled this state "vesania katatonica". ${ }^{2}$ Stressing that catatonia was not related to "affective" melancholy sensu strictu, Wernicke suggested the term "motilitåtpsychose", and suggested that this disorder may be the result of dysfunction of a "psychomotor path", producing either akinesis, parakinesis, or hyperkinesis. ${ }^{3}$ Whereas Kahlbaum and Wernicke placed catatonia within the range of the affective disorders, Kraepelin ${ }^{4}$ considered catatonia as a type of schizophrenia, and this disorder aroused little interest until recently.

In a series of studies, Taylor and Abrams ${ }^{5}$ and Abrams and Taylor ${ }^{6}$ found catatonic signs such as stereotypies, posturing, catalepsy, automatic obedience, negativism, echolalia, echopraxia, or stupor in more than a quarter of a consecutive series of patients with mania. In a study that included 55 consecutive psychiatric admissions of patients featuring one or more catatonic signs, Abrams and Taylor found that over two thirds had an affective disorder. ${ }^{6}$ On the other hand, motor disorders have often been reported in depressed patients. Rogers et $a l^{7}$ showed that patients with primary depression and newly diagnosed patients with Parkinson's disease had a slower response on a computerised task than normal control subjects. A follow up evaluation six months later showed that both in patients with Parkinson's disease and in depressed patients, improvement in mood was significantly associated with improvement on the psychomotor task. Fleminger ${ }^{8}$ also showed that patients with depressive motor retardation had raised scores on a clinical rating scale of parkinsonian signs, but he also found significant differences between the movement disorder in depressed patients and that in patients with Parkinson's disease.

Despite these important studies, several issues regarding catatonia still remain unsolved. Firstly, there is only one structured scale for the assessment of catatonic signs (the modified Rogers scale (MRS) $)^{9}$ and this scale has only been assessed with schizophrenic patients. Secondly, whether the DSM-IV ${ }^{10}$ criteria of catatonia (catatonic features specifier of mood disorder) can distinguish depressed patients with catatonia from phenomenologically similar disorders (for example, severe 
Parkinson's disease) has not been examined. Thirdly, the clinical correlates of catatonia in depressed patients have hardly been considered, and the mechanism is still unknown.

In this study we examined a consecutive series of 79 patients with depression for the presence of catatonia using a comprehensive psychiatric and neurological evaluation that included the MRS and the UPDRS. ${ }^{11}$ To determine the validity of the DSM-IV criteria of catatonia we also examined a consecutive series of 41 non-depressed patients with Parkinson's disease. Finally, we assessed the response to apomorphine in a sample of catatonic patients and patients with Parkinson's disease to examine the importance of dopaminergic dysfunction in the mechanism of catatonia.

\section{Patients and methods \\ PATIENTS \\ Depression group}

This group included a consecutive series of 79 patients that were examined in the Department of Neuropsychiatry at the Raúl Carrea Institute of Neurological Research because of depression. Our institute provides psychiatric care to a large section of Buenos Aires and is not a tertiary care centre. Patients with depression seen at our institute are representative of a normal psychiatric population and are not more likely to have coexisting neurological disorders or other medical conditions. Patients included in this group had to meet the DSM-III-R ${ }^{12}$ criteria for either major depression, bipolar disorder-mixed, bipolar disorder-depressed, or dysthymia. All patients underwent CT or MRI, and none of them had structural brain lesions.

\section{Parkinson's disease group}

This group consisted of 41 consecutive patients with Parkinson's disease and no depression that were seen in the neurology clinic of our institute at regular follow ups. All patients had positive clinical responses to levodopa.

\section{PSYCHIATRIC EXAMINATION}

After informed consent and blind to neurological findings, depressed patients and patients with Parkinson's disease were assessed with the following tests:

\section{Structured clinical interview for DSM-III-R (SCID) ${ }^{13}$}

The SCID is a semistructured diagnostic interview for major axis I DSM-III-R ${ }^{12}$ diagnoses.

Present state exam (PSE) ${ }^{14}$

The PSE is a semistructured psychiatric interview which was rated by a psychiatrist with the patient and at least one first degree relative.

Research diagnostic criteria, family history $(R D C-F H)^{15}$

To obtain a family history of psychiatric disorders for the patients' first and second degree relatives, two first degree relatives were interviewed. Diagnoses of axis I disorders were made based on the RDC-FH.

\section{Hamilton depression and anxiety scales} (HAM-D, HAM-A) ${ }^{1617}$

The HAM-D and HAM-A are interviewer rated scales that measure symptoms of depression and anxiety.

Mini mental state examination (MMSE) ${ }^{18}$

The MMSE is an 11 item examination found to be valid and reliable in assessing global cognitive deficits.

\section{Functional independence measure (FIM) ${ }^{19}$}

The FIM assesses self care, sphincter control, mobility, locomotion, communication, and social cognition. Higher scores indicate less impairment in activities of daily living.

\section{Social ties checklist (STC) ${ }^{20}$}

This is a 10 item scale which assesses the quantity and quality of social supports. Scores range from 0 to 10 , and higher scores indicate better social supports.

\section{Diagnosis of catatonia}

The diagnosis of catatonia (catatonic features specifier of the DSM-IV) was made by the psychiatrist based on the PSE findings. The PSE includes a section that rates the presence of catatonic signs such as self neglect, bizarre appearance, slowness and underactivity, agitation, gross excitement and violence, distractibility, mannerisms, posturing, and stereotypies. These signs are rated 0 (symptom absent), 1 (present in fairly severe degree, or very severe but intermittent during interview), and 2 (present in very severe degree and almost continuous during interview). The psychiatric evaluation was carried out immediately before or after the neurological examination.

\section{NEUROLOGICAL EXAMINATION}

The neurological evaluation was carried out by a neuropsychiatrist blind to the psychiatric data, and consisted of the following items:

\section{Unified Parkinson's disease rating scale} (UPDRS) ${ }^{11}$

This scale has three sections: activities of daily living, motor examination, and complications of antiparkinsonian treatment. Item scores range from 0 to 4 , and higher scores indicate more severe impairment. To assess patients with Parkinson's disease with a wide variety of extrapyramidal signs and dyskinaesiae, the neurological examination was carried out regardless of the interval since the last dose of levodopa.

\section{Modified Rogers scale (MRS) ${ }^{9}$}

This is a 36 item scale that rates clinical signs usually described in catatonic patients, such as disorders of posture (for example, posturing and waxy flexibility), muscular and motor compliance (for example, "gengenhalten", "mitgehen"), movements of the head, face, 
trunk, and limbs (for example, mannerisms and stereotypies), ocular movements (for example, to and fro roving movements), purposive movements (for example, abruptness, slowness, exaggerations, iterations, echopraxia, blocking, ambitendence), gait (for example, manneristic, bizarre), speech (for example, mutism, echolalia, palilalia, speech mannerisms), behaviour during interview (for example, automatic obedience, negativism), and reported behaviour (for example, under or overactivity, repetitive acts, and rituals). These items are rated 0 (abnormality absent), 1 (abnormality definitely present), and 2 (abnormality pronounced or pervasive). This scale shows an excellent between rater and within rater reliability, as well as good internal consistency. ${ }^{9}$

\section{APOMORPHINE TEST ${ }^{21}$}

This evaluation was carried out by a neurologist who was blind to psychiatric data and group membership. A consecutive series of seven patients with catatonia and 11 patients with Parkinson's disease received $60 \mathrm{mg}$ of domperidone daily for at least 48 hours before the test. A basal examination was carried out in the fasting state at $900 \mathrm{am}$. This consisted of measurements on the Webster scale ${ }^{22}$ and the MRS. The Webster scale measures motor disabilities such as bradykinesia, rigidity, posture, arm swing, gait, tremor, facial movements, speech, balance, dyskinesiae, and dystonias. Higher scores indicate more severe impairment. After the basal assessment, $3 \mathrm{mg}$ of apomorphine were injected subcutaneously, and the neurological assessment was repeated 30 minutes after the injection. Patients with Parkinson's disease were reported to show significant improvements in motor function 15 minutes after the injection, with a peak response 30 minutes after injection. ${ }^{21}$

STATISTICAL ANALYSIS

Statistical analysis was carried out on means and SDs by multivariate analysis of variance (MANOVA), post hoc planned comparisons, and a Bonferroni correction for multiple comparisons. Frequency distributions were compared using $\chi^{2}$ with a Yates' correction for cell sizes $<5$, Fisher's exact tests, and contingency tables. Regressions were calculated by a

Table 1 Demographic and psychiatric findings

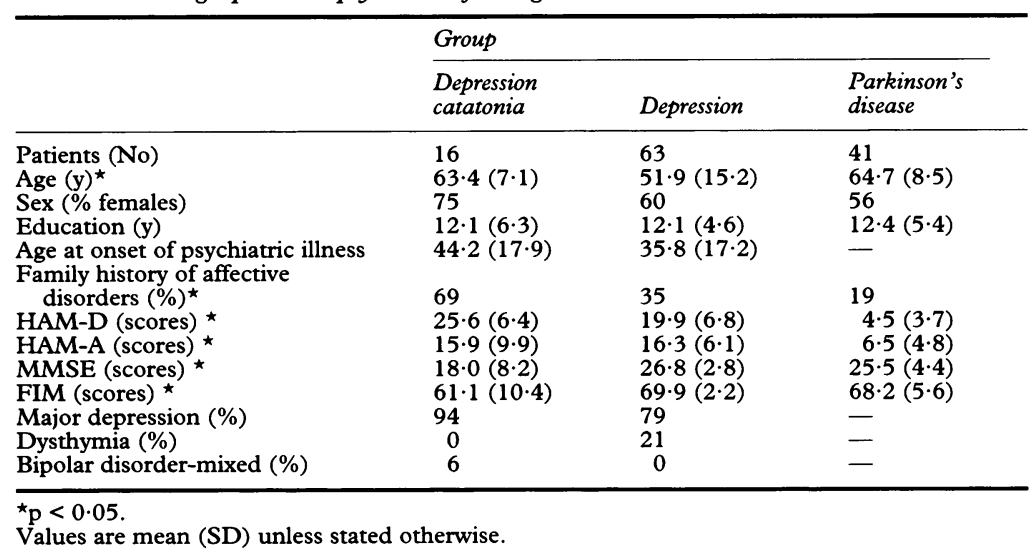

forward stepwise regression analysis, and a factor analysis was calculated using a Varimax rotation. All $P$ values are two tailed.

\section{Results}

PREVALENCE

Based on PSE findings, sixteen of the 79 depressed patients $(20 \%)$ met the DSM-IV criteria for catatonia compared with none of the 41 patients with Parkinson's disease $\left(\chi^{2}\right.$ Yates $=7.91, \mathrm{df}=1, \mathrm{P}=0.004)$. Table 1 shows the demographic and psychiatric data. Patients with catatonia were significantly older $(F=15 \cdot 0, \mathrm{df}=2,117, \mathrm{P}<0.0001)$, had significantly lower MMSE scores $(F=24 \cdot 9$, df $=2,117, \mathrm{P}<0.0001$ ), and had significantly more severe impairments in activities of daily living $(F=13.8, \quad \mathrm{df}=2,117, \quad \mathrm{P}<0.0001)$ than depressed non-catatonic patients and patients with Parkinson's disease. Depressed patients with catatonia had significantly higher HAM-D scores than both depressed non-catatonic patients and patients with Parkinson's disease, whereas depressed non-catatonic patients had significantly higher HAM-D scores than patients with Parkinson's disease $(\mathrm{F}=106 \cdot 7, \mathrm{df}=2,117, \mathrm{P}<0.0001)$. There were no significant differences between depressed-catatonic and depressed non-catatonic patients in HAM-A scores, but both groups had significantly higher scores than patients with Parkinson's disease $(F=27 \cdot 9$, $\mathrm{df}=2,117, \mathrm{P}<0.0001)$. Finally, depressed patients with catatonia showed a significantly higher frequency of familial history of affective disorders than depressed non-catatonic patients and patients with Parkinson's disease $\left(\chi^{2}=12 \cdot 4, \mathrm{df}=2, \mathrm{P}=0.001\right)$.

\section{PHENOMENOLOGY}

To examine whether age, motor impairments (as measured with the UPDRS), and severity of depression were significantly correlated with catatonia we carried out a forward stepwise regression analysis using the MRS total scores as the dependent variable, and age, UPDRS motor scores, and HAM-D scores as the independent variables. The regression analysis was significant (multiple $R=0.72, \mathrm{df}=115$, $P<0.0001)$ and all three independent variables accounted for a significant part of the variance (motor UPDRS $R^{2}=0.35$, $\mathrm{df}=115, \mathrm{P}<0.0001 ;$ HAM-D $R^{2}=0.16, \mathrm{df}$ $=115, \mathrm{P}<0.0001$; and age $R^{2}=0.02$, df $=$ $115, P=0.05)$. To examine the validity of the catatonia construct while controlling for the above variables, depressed patients with catatonia $(n=16)$ and depressed non-catatonic patients $(n=16)$ were matched for age $( \pm 5$ years) and HAM-D scores ( \pm 4 points), and depressed-catatonic and patients with Parkinson's disease $(\mathrm{n}=16)$ were matched for age ( \pm 5 years) and UPDRS motor scores ( \pm 4 points).

Antidepressant drugs were used by six depressed patients with catatonia, six depressed non-catatonic patients, and one patient with Parkinson's disease. Three depressed patients with catatonia and one 
Table 2 Mean scores for the five DSM-IV clusters of catatonic features specifier in mood disorders, and scoring algorithm based on the Rogers catatonia scale scores

\begin{tabular}{|c|c|c|c|}
\hline & \multicolumn{3}{|l|}{ Group } \\
\hline & $\begin{array}{l}\text { Depression } \\
\text { catatonia }\end{array}$ & Depression & $\begin{array}{l}\text { Parkinson's } \\
\text { disease }\end{array}$ \\
\hline Number of patients & 16 & 16 & 16 \\
\hline Motor immobility & $1 \cdot 81(1 \cdot 04)$ & $0 \cdot 18(0 \cdot 40)$ & $0.06(0.25)$ \\
\hline Range & $0-3$ & $0-1$ & $0-1$ \\
\hline $\begin{array}{l}\text { Excessive motor activity } \\
\text { Range }\end{array}$ & $\begin{array}{l}0.50(0.73) \\
0-2\end{array}$ & $0 \cdot 0$ & $0 \cdot 0$ \\
\hline Extreme negativism or mutism $\ddagger$ & $1.18(0.91)$ & $0.06(0.25)$ & $0.06(0.25)$ \\
\hline Range & $0-3$ & $0-1$ & $0-1$ \\
\hline \multicolumn{4}{|l|}{$\begin{array}{l}\text { Posturing, stereotypies, prominent } \\
\text { mannerisms, or prominent }\end{array}$} \\
\hline grimacing 5 & $2 \cdot 12(1 \cdot 31)$ & $0 \cdot 18(0 \cdot 40)$ & $0 \cdot 18(0 \cdot 40)$ \\
\hline Range & $1-5$ & $0-1$ & $0-1$ \\
\hline Echolalia or echopraxiađ & $0.81(0.75)$ & 0.0 & 0.0 \\
\hline Range & $0-2$ & & \\
\hline
\end{tabular}

Values are means (SD) unless otherwise stated.

^Score 2 points on items 3 and/or 19 (range 0-4 points) (see table 4).

†Score 1 or 2 points on item 18 (range $0-2$ points).

$\ddagger$ Score 2 points on items 15 and/or 20 (range $0-2$ points).

Score 2 points on items $1,2,5,6$, and/or 8 (range $0-10$ points)

SScore 1 or 2 points on items 11 and/or 17 (range 0-2 points).

depressed non-catatonic patient were taking neuroleptic drugs. Benzodiazepines were used by six depressed patients with catatonia, 10 depressed non-catatonic patients, and three patients with Parkinson's disease. One patient (with catatonia) was taking lithium. Thirteen of the 16 patients with Parkinson's disease were taking levodopa (dose range: 250-1000 $\mathrm{mg} /$ day).

The DSM-IV diagnostic criteria for the catatonic features specifier require at least two of the following five clusters: (1) waxy flexibility (rated in item 3 of the MRS) or stupor (rated in item 30 of the MRS), (2) excessive motor activity (rated in item 29 of the MRS), extreme negativism (rated in item 33 of the MRS), or mutism (rated in item 26 of the MRS), (4) posturing (rated in item 2 of the MRS), stereotyped movements, grimacing, and mannerisms (rated in items 9 and 12 of the MRS), and (5) echolalia (rated in item 28 of the MRS) and echopraxia (rated in item 20 of the MRS). To examine whether these five clusters discriminate depressed patients with catatonia $(n=16)$ from patients with Parkinson's disease with a similar motor impairment $(n=16)$ and depressed patients with a similar severity of depression $(n=16)$, we carried out a MANOVA (group $\times$ DSMIV clusters). There was a significant overall effect (Wilks' $\lambda=0 \cdot 10, \quad \mathrm{df}=12,80$,

Table 3 Modified Rogers scale items that showed significant differences between depressed patients with catatonia, depressed non-catatonic patients, and patients with Parkinson's disease

Aprosodic speech $(F=40 \cdot 0, \mathrm{df}=2,45, \mathrm{P}<0.0001)$

Persistence of imposed postures $(F=28 \cdot 3, \mathrm{df}=2,45, \mathrm{P}<0.0001)$

Simple abnormal posture $(F=20 \cdot 3, \mathrm{df}=2,45, \mathrm{P}<0.0001)$

Simple and brief dyskinesia-like movements of face and head $(F=16.0, \mathrm{df}=2,45, \mathrm{P}<0.0001)$

Mutism $(F=15.9, \mathrm{df}=2,45, \mathrm{P}<0.0001)$

Indistinct/unintelligible speech $(F=15 \cdot 0, \mathrm{df}=2,45, \mathrm{P}<0.0001)$

Reduced associated movements during gait $(F=14.0, \mathrm{df}=2,45, \mathrm{P}<0.0001)$

Slow/shuffling gait $(F=13.1$, df $=2,45, \mathrm{P}<0.0001)$

Slow/shuffling gait $(F=13 \cdot 1, \mathrm{df}=2,45, \mathrm{P}<0.0001)$

Reported overactive behaviour $(F=12 \cdot 5, \mathrm{df}=2,45, \mathrm{P}<0.0001)$
Simple and brief dyskinesia-like movements of trunk and limbs $(F=11 \cdot 9, \mathrm{df}=2,45$, $\mathrm{P}<0.0001)$

Slowness/feebleness of spontaneous movements $(F=11 \cdot 1, \mathrm{df}=2,45, \mathrm{P}<0.0001)$

Mitgehen $(F=10.9, \mathrm{df}=2,45, \mathrm{P}<0.0001)$

Marked underactivity $(F=9.94, \mathrm{df}=2,45, \mathrm{P}<0.0001)$

Complex mannerisms or stereotypies of face and head $(F=9.61, \mathrm{df}=2,45, \mathrm{P}<0.001)$

Reported underactive behaviour $(F=8.98, \mathrm{df}=2,45, \mathrm{P}<0.0001)$

Echolalia $(F=7.92, \mathrm{df}=2,45, \mathrm{P}<0.001)$

Iterations of spontaneous movements $(F=7.90, \mathrm{df}=2,45, \mathrm{P}<0.001)$

Marked overactivity $(F=7.81, \mathrm{df}=2,45, \mathrm{P}<0.001)$
$\mathrm{P}<0.0001)$. Whereas depressed patients with catatonia showed significantly higher scores in each of the five clusters than non-catatonic patients and patients with Parkinson's disease, no significant differences were found between depressed non-catatonic patients and patients with Parkinson's disease in any of the five clusters (table 2).

Significant between group differences in individual MRS items were analysed with a two way ANOVA with repeated measures (group: depression and catatonia, Parkinson's disease, depressed non-catatonic patients; repeated measures: MRS items). There was a significant group effect $(F=110.6, \mathrm{df}=$ $2,45, P<0.0001)$, and a significant group $\times$ MRS interaction $(F=3.55, \mathrm{df}=70,1575$, $\mathbf{P}<0.0001)$. Depressed patients with catatonia had significantly higher MRS scores than the other two groups, but no significant differences were found between patients with Parkinson's disease and depressed non-catatonic patients. Table 3 presents those MRS items that showed significant between group differences (to adjust the $\alpha$ level for the number of comparisons, a Bonferroni correction for multiple comparisons was carried out (36 comparisons, threshold set at $P=0.0013)$ ).

Based on the above findings we modified the MRS, keeping those items that are necessary for a DSM-IV diagnosis of catatonia, and adding those items that showed significant between group differences. This modified scale (Rogers catatonia scale (RCS)) (table 4) was then examined for its reliability and validity. A score $>7$ separated depressed patients with catatonia $(n=16)$ from patients with Parkinson's disease with a similar severity of motor impairment $(n=16)$, and depressed non-catatonic patients with a similar severity of depression $(n=16)$, with a sensitivity and specificity of $100 \%$ (all 16 depressed patients with catatonia but none of the depressed non-catatonic or patients with Parkinson's disease had an RCS >7). The RCS scores (mean (SD)) were: depressed-catatonic group $10.8(2.7)$, depressed non-catatonic group 0.6 $(1 \cdot 3)$, and Parkinson's disease group $0.6(1.3)$ $(F=147 \cdot 6, \mathrm{df}=2,45, \mathrm{P}<0.0001)$.

To substantiate Abrams and Taylor's suggestion regarding the existence of two factors in catatonia (hyperactive and hypoactive), we carried out a factor analysis of the RCS which included all 79 depressed patients (with or without catatonia). A Varimax rotation produced two factors (table 5): factor 1 had an eigenvalue of 6.09 and explained $44 \%$ of the variance. This factor loaded $(>0.70)$ on the following items: simple abnormal postures, persistence of imposed postures, reduced associated movements during gait, aprosodic speech, mutism, and pronounced underactivity. Thus this factor can be construed as a hypoactivity factor. Factor 2 had an eigenvalue of 2.83 and explained $20 \%$ of the variance. This factor loaded $(>0.70)$ on the following items: complex mannerisms or stereotypies of trunk, face, head, and limbs, echolalia, and pronounced hyperactivity. Thus this factor can be construed as a hyperactivity factor. 
Table 4 Rogers catatonia scale

Unless otherwise specified, items should be rated as follows: 0 abnormality absent, 1 abnormality definitely present, 2 abnormality pronounced or pervasive (see definitions and examples in Lund et $a l^{9}$ )

\section{Simple abnormal posture}

Complex abnormal posture

Persistence of imposed postures:

0 absent; 1 not sustained; 2 waxy flexibility

Mitgehen

Simple brief dyskinesia-like movements of face and head

Complex mannerisms or stereotypies of face and head

Simple brief, dyskinesia-like movements of trunk and limbs

Complex mannerisms or stereotypies of trunk and limbs

Slowness/feebleness of spontaneous movements

Iterations of spontaneous movements

Echopraxia

Reduced associated movements during gait

Slow/shuffling gait

Aprosodic speech

Mutism:

0 normal speech; 1 less than 20 words during the interview; 2 mutism

Verbigeration

Echolalia

Marked overactivity:

0 absent; 1 in constant motion; 2 catatonic excitement

Marked underactivity:

0 absent; 1 sits still and passive; 2 catatonic stupor

Negativism

Reported overactive behaviou

Reported underactive behaviour
The reliability of the RCS was assessed by two neuropsychiatrists who evaluated five depressed non-catatonic and five depressed patients with catatonia in separate sessions. The interrater reliability was high (intraclass $r=0.81)$. The intrarater reliability was assessed by a neuropsychiatrist who examined five depressed non-catatonic patients and five depressed patients with catatonia in two sessions, two to seven days apart, and was found to be high (intraclass $r=0.89$ ). Finally, we also calculated the internal reliability of the RCS, which was also high (Cronbach $\alpha=$ $0 \cdot 87$ ).

We examined whether the profile of extrapyramidal signs was different in catatonic patients $(n=16)$, patients with Parkinson's disease $(n=16)$, and depressed non-catatonic patients $(n=16)$. A two way ANOVA with repeated measures for UPDRS scores (group: depressed-catatonic patients, depressed non-catatonic patients, and patients with Parkinson's disease; repeated measures: UPDRS motor items) showed a significant group effect $(F=15 \cdot 7, \mathrm{df}=2,45, \mathrm{P}<0.0001)$; patients with catatonia or Parkinson's disease showed significantly higher overall motor scores than depressed non-catatonic patients. A two way ANOVA with repeated measures for patients with catatonia or Parkinson's disease showed a significant group $\times$ UPDRS motor item interaction $(F=2.35$, df $=13,390, P=0.004$; patients with Parkinson's disease had significantly higher tremor scores than depressed

Table 5 Rogers catatonia scale: factor loadings (varimax normalised)

\begin{tabular}{lcr}
\hline Item & Factor 1 & Factor 2 \\
\hline Simple abnormal postures & $0 \cdot 78$ & $0 \cdot 26$ \\
Persistence of imposed postures & $0 \cdot 72$ & $0 \cdot 27$ \\
Reduced associated movements during gait & $0 \cdot 86$ & 0.06 \\
Aprosodic speech & $0 \cdot 82$ & 0.33 \\
Mutism & 0.95 & $0 \cdot 12$ \\
Marked underactivity & $0 \cdot 81$ & -0.12 \\
Complex mannerisms of face and head & $0 \cdot 14$ & $0 \cdot 79$ \\
Complex mannerisms of trunk and limbs & -0.02 & $0 \cdot 85$ \\
Echolalia & $0 \cdot 12$ & 0.84 \\
Marked hyperactivity & -0.02 & 0.94 \\
\hline
\end{tabular}

patients with catatonia $(F=4 \cdot 80, \mathrm{df}=1,30$, $\mathrm{P}<0.05)$ ), but no significant between group differences were found on the remaining UPDRS items.

\section{APOMORPHINE TEST}

A two way ANOVA with repeated measures (group: depression and catatonia $(\mathbf{n}=7) v$ Parkinson's disease $(\mathrm{n}=11)$, repeated measure: total Webster scale score before and 30 minutes after apomorphine injection) showed no significant group effect $(F=0 \cdot 01, \mathrm{df}=$ $1,16, \mathrm{NS}$; both groups showed a similar overall severity of extrapyramidal signs), and a significant group $\times$ time interaction $(F=4.96, \mathrm{df}=$ $1,16, \mathrm{P}<0.05)$. Whereas patients with Parkinson's disease showed a significant improvement in Webster scale scores $30 \mathrm{~min}-$ utes after the apomorphine injection (preapomorphine score (mean (SD) 15.3 (8.8), postapomorphine score $7 \cdot 2 \quad(4 \cdot 13) ; \mathrm{P}=$ 0.001 ), depressed patients with catatonia showed no significant improvement (preapomorphine score $12.8(10 \cdot 6)$, postapomorphine score $10 \cdot 7(10 \cdot 8)$, NS). Moreover, no significant changes in total RCS scores or in individual RCS items were found in the depressed patients with catatonia before and 30 minutes after the apomorphine injection (RCS scores (mean (SD)) 12.1 (2.7) and 11.8 (1.9), respectively).

\section{Discussion}

We examined the clinical correlates of catatonia in patients with depression, as well as the validity of both the Rogers catatonia scale and the DSM-IV criteria for the catatonic features specifier of mood disorders. There were several important findings. Firstly, $20 \%$ of a consecutive series of depressed patients met the DSM-IV criteria for catatonia. Secondly, the RCS was found to be a valid instrument to assess the presence and severity of catatonia. Thirdly, the DSM-IV criteria of catatonia had a high specificity for this phenomenon, as depressed patients with catatonia showed significantly higher scores in each DSM-IV cluster for the catatonic features specifier than patients with Parkinson's disease and a similar motor impairment. Fourthly, apomorphine did not improve catatonic signs.

Some limitations of our study should be pointed out. Three patients with catatonia were on neuroleptic drugs, which may have produced some of the abnormal motor signs. However, all three patients were on low dosages of neuroleptic drugs (as also was one non-catatonic depressed patient), and all three showed a significant improvement in catatonic signs after electroconvulsive therapy. In patients with Parkinson's disease the psychiatric evaluation was carried out regardless of the interval since levodopa intake. Although this may have introduced some variability in the psychiatric results, we only included patients with Parkinson's disease that were not depressed at the time of the evaluation. Finally, the modification of the RCS was based on a small sample, which may have 
resulted in an artificially high sensitivity and specificity, and this important issue should be examined in a separate sample.

The nosological position of catatonia has been the subject of debate ever since Kraepelin ${ }^{4}$ included catatonia as a type of schizophrenia. Although several anecdotal studies suggested that patients with affective disorders may also show catatonia, Abrams and Taylor ${ }^{6}$ were the first to show that catatonia was significantly more frequent among patients with affective disorders than among patients with schizophrenia. This fact was acknowledged in the DSM-IV, which includes catatonia as a modifier for mood disorders. However, several issues regarding catatonia still remain unsolved. No structured instrument for the diagnosis of catatonia among patients with affective disorders has been validated, and whether the DSM-IV criteria of catatonia allow the distinction between patients with catatonia and similar motor disorders such as Parkinson's disease had not been previously examined.

Our study validates the Rogers catatonia scale for the diagnosis of catatonia in depressed patients. When depressed patients with catatonia were compared with patients with Parkinson's disease with a similar severity of motor impairments and depressed noncatatonic patients with a similar severity of depression, the depressed-catatonic group showed significantly higher RCS scores. Moreover, a score $>7$ separated depressed patients with catatonia from the other two groups with a sensitivity and specificity of $100 \%$.

We also examined whether the DSM-IV criteria for catatonia distinguished depressed patients with catatonia from patients with Parkinson's disease. This is important, because, except for tremor, there were no other significant differences in the severity of extrapyramidal signs between these two groups. We found that even after patients with catatonia and non-depressed patients with Parkinson's disease were matched for motor scores (rigidity, tremor, slowness of movements, gait disturbance, posture, and body balance) the DSM-IV criteria for catatonia had a high specificity (none of the patients with Parkinson's disease were diagnosed as having catatonia). This finding suggests that the mechanism causing catatonia in depressed patients may not involve dysfunction of the nigrostriatal dopaminergic pathways, which is also supported by the findings from the apomorphine test. Whereas patients with Parkinson's disease showed a significant improvement in extrapyramidal signs $30 \mathrm{~min}$ utes after the subcutaneous injection of $3 \mathrm{mg}$ of apomorphine, no significant changes in Webster or RCS scores were found in depressed patients with catatonia. Alternatively, the negative results after the apomorphine injection may be explained by postsynaptic changes in dopamine receptors, and this possibility should be examined in future studies using PET and radiolabelled dopamine ligands.
We also confirmed Abrams and Taylor's suggestion of two factors in catatonia (hyperactivity and hypoactivity). It is well known that some patients may switch from a period of catatonic stupor to a period of catatonic excitement, thus reproducing in the motor domain the sequence of affective changes present in depressive-manic illness. Whether the hyperactivity and hypoactivity factors of catatonia share a common mechanism (for example, abnormal inhibition or release of motor behaviours) should be further examined.

The question that now arises is what is the mechanism of catatonia in affective disorders? Although this study was not specially aimed at answering this important question, we found that depressed patients with catatonia were significantly older, had a significantly more severe depression, greater cognitive impairments, and a higher frequency of familial history of affective disorders than depressed patients without catatonia. Although age may be a predisposing factor, it does not seem to be either necessary or sufficient, as most elderly patients with depression do not show catatonia. However, a combination of age and a genetic burden may interact with still unknown factors to produce catatonia.

In conclusion, $20 \%$ of a consecutive series of patients with depression met the DSM-IV criteria of catatonia. These criteria distinguished depressed patients with catatonia from non-depressed patients with Parkinson's disease and similar motor impairments with a specificity of $100 \%$. The present study also showed the validity and reliability of the RCS to diagnose and rate the severity of catatonia. Finally, catatonia was significantly associated with age, more severe depression, and greater cognitive impairments, and it was not improved by the use of dopaminergic agonists. Future studies should examine the neurobiological basis of this phenomenon.

This study was partially supported by a grant from the Raúl Carrea Institute of Neurological Research and the Fundacion Perez Companc. We thank Dr Robert G Robinson for his valuable suggestions.

1 Baillarger JG. De l'etat désigné chez les aliénés sous le nom de stupidité. In: Recherches sur les maladies mentales. Paris: Masson, 1843.

2 Kahlbaum KL. Die Katatonie oder das Spannungsirreseins. Berlin: Hirschwald, 1874.

3 Wernicke C. Grundriss der Psychiatrie. Leipzig: Thieme, 1900.

4 Kraepelin E. Die Erscheinungsformen des Irreseins. Zeitschrift für des gesamte Neurologie und Psychiatre 1920; 6eitschrif

5 Taylor MA, Abrams. R. Catatonia: prevalence and importance in the manic phase of manic-depressive illness. Arch Gen Psychiatry 1977;34:1223-5.

6 Abrams R, Taylor MA. Catatonia, a prospective clinica study. Arch Gen Psychiatry 1976;33:579-581.

7 Rogers D, Lees AJ, Smith E, Trimble M, Stern GM Bradyphrenia in Parkinson's disease and psychomotor retardation in depressive illness: an experimental study. Brain 1987;110:761-76.

8 Fleminger S. Control of simultaneous movements distinguishes depressive motor retardation from Parkinson's disease and neuroleptic parkinsonism. Brain 1992;115: 1459-80.

9 Lund CE, Mortimer AM, Rogers D, McKenna PJ. Motor, volitional and behavioural disorders in schizophrena: 1: assessment using the modified Rogers scale. $\mathrm{Br} \mathscr{\jmath}$ assessment using the modifich
Psychiatry 1991;158:323-7.

10 American Psychiatric Press. Diagnostic and statistical manual for mental disorders (DSM-IV). 4th ed. Washington, DC: APA, 1994.

11 Fahn S, Elton E, UPDRS Development Committee. Unified Parkinson's disease rating scale. In: Fahn S, Marsden CD, Goldstein M, Calne CD, eds. Recent devel 
opments in Parkinson's disease. Florham Park, NJ: Macmillan, 1987: 153-63.

. for mental disorders (DSM-III-R). 3rd ed (rev). for mental disorders (DSM

13 Spitzer RL, Williams JBW, Gibbon M, First MB. The structured clinical interview for DSM-III-R (SCID). I: history, rationale, and description. Arch Gen Psychiatry 1992;49:624-9.

14 Wing JK, Cooper E, Sartorius N. Measurements and classification of psychiatric symptoms. Cambridge: Cambridge University Press, 1974

15 Spitzer R, Endicott J, Robins E. Research diagnostic criteria (RDC) for a group of functional disorders. New York: Biometrics Research Division, New York Psychiatric Institute, 1975.

16 Hamilton MA. A rating scale for depression. 7 Neurol Neurosurg Psychiatry 1960;23:56-62.
17 Hamilton MA. The assessment of anxiety states by rating. Br f Med Psychol 1959;32:50-5.

18 Folstein MF, Folstein SE, McHugh PR. Mini-Mental state: a practical method for grading the cognitive state of patients for the clinician. $\mathcal{F}$ Psychiat Res 1975;12: of patients

19 Granger CV, Hamilton BB, Kayton R. Guide for use of the uniform data set for medical rehabilitation. Buffalo, NY: Uniform Data System for Medical Rehabilitation, 1986

20 Starr LB, Robinson RG, Price TR. Reliability, validity and clinical utility of the Social Functioning Exam in the assessment of stroke patients. Exp Aging Res 1983;9: 101-10.

21 Hughes AJ, Lees AJ, Stern GM. Apomorphine test to predict responsiveness in parkinsonian syndromes. Lancet 1990; ii:32-4.

22 Webster DD. Critical analysis of the disability in Parkinson's disease. Modern Treatment 1968;5:257-82.

\section{Notes on tetanus (lockjaw)}

Tetanus (Greek tetanos, derived from teinein to stretch) appears through the ages in military medicine. Slapping infected dung on to the newborn umbilical cord caused tetanus neonatorum or "trismus nascentium" to be rampant in the West Indies and Africa. Osler's textbook describes the "eight days sickness" caused by umbilical sepsis, which in St Kilda killed 84 of 125 children within a fortnight of birth. ${ }^{1}$ In the first world war it occurred in 1.47 per 1000 of the British wounded, and in 12.5 per 1000 in the Peninsular campaign. ${ }^{2}$

In an earlier battle, Sir Charles Bell's famous war illustration portrays tetanus in a soldier during Sir John Moore's retreat to Corunna.

Risus sardonicus hails from the sneering grin thought to resemble the effect of a Sardinian rununculus, which on being chewed contorted the face of the eater. The anaerobic bacillus Clostridium tetani was discovered by Nicolaier in 1885. In 1889 Koch's pupil Kitasato obtained the bacillus of tetanus in pure culture and conveyed the disease to animals.

Antitoxin was quickly recognised by Thomas Clifford Allbutt (System of Medicine 1896;1:237): "The diphtheria and tetanus antitoxins act directly on the toxins." Antitetanus serum was in general use before the first world war, but the dose was variable. And the intrathecal, intravenous, or intramuscular routes each had its proponents. The mortality was still between $37 \%$ and $50 \%$.

Ancient descriptions are impressive:

\section{Hippocrates}

"The master of a large ship mashed the index finger of his right hand with the anchor. Seven days later a somewhat foul discharge appeared; then trouble with his tongue-he complained he could not speak properly. The presence of tetanus was diagnosed, his jaws became pressed together, his teeth were locked, then symptoms appeared in his neck; on the third day opisthotonos appeared with sweating. Six days after the diagnosis was made he died"

In the Aphorisms (c $380 \mathrm{BC}$ ): ${ }^{4}$ section V 2, "Spasm supervening on a wound is fatal." And section V 6, "Such persons as are seized with tetanus either die within four days, or if they pass these they recover".

\section{Aretaeus}

An inhabitant of Cappadocia (1st century AD), an ancient kingdom of Asia Minor, Aretaeus left this wonderful characterisation: ${ }^{5}$

"Tetanus in all its varieties, is a spasm of an exceedingly painful nature, very swift to prove fatal, but neither easy to be removed.... There are three forms of the convulsions, namely in a straight line, backwards and forwards ... there is tension in a straight line of the whole body, which is unbent and inflexible....

Opisthotonos bends the patient backward, like a bow, so that the reflected head is lodged between the shoulder-blades; the throat protrudes; the jaw sometimes gapes, ... respirations stertorous; the belly and chest prominent ... the abdomen stretched, and resonant if tapped; the arms strongly bent back in a state of extension; the legs and thighs are bent together....

The causes of these complaints are many; for some are apt to supervene on the wound of a membrane, or of muscles,.... And women also suffer from this spasm after abortion; and in this case they seldom recover . ...

In all of these varieties then, there is pain and tension of the tendons and spine, and of the muscles connected with the jaws and cheek; for they fasten the lower jaw to the upper, so that it cannot easily be separated even with levers or a wedge. But if one by forcibly separating the teeth, pour in some liquid the patients do not drink it but squirt it out . . . .

But if they are bent forward (Emprosthotonos), they are protuberant at the back, the loins being extruded in a line with the back, the whole spine being straight; . . . the lower jaw fixed on the breast bone; the hands clasped together, the lower extremities extended; pains intense; the voice altogether dolorous. Should the mischief then seize the chest and respiratory organs, it readily frees the patient from life...

"An inhuman calamity! an unseemly sight! ... But neither can the physician, furnish any assistance, as regards life, relief from pain or from deformity." J M S PEARCE
304 Beverley Road, Anlaby,
Hull HU1O $7 B G, U K$

1 Osler W. Principles and practice of medicine. 1898. 2 Official history of the war (Pathology, 1923), cited by Wilson SAK, In: Neurology. London: Arnold, 1940:626. Beck T. Hippokrates Erkenntnisse. Jena: Diedrichs, 1907:132. 3 Beck T. Hippokrates Erkenntnisse. Jena: Diedrichs, 1907:132. Adams F. Aphorisms. In: The genuine works of Hippocrate
Vol 2. London: The Sydenham Society 1849:737-8.

Vol 2. London: The Sydenham Society 1849:737-8. Adams F. The extant works of Aretaeus, the Cappadocian.
Edited and translated, London: The Sydenham Society, Edited and
1856:253. 